\title{
Prescription pattern in cases of ischemic stroke in general medicine department in Government General Hospital, Kakinada, Andhra Pradesh
}

\author{
Suvvada Vamsi Jagannath, D. Vijayalakshmi*
}

Department of Pharmacology, Rangaraya Medical College, Kakinada, Andhra Pradesh, India

Received: 09 January 2020

Revised: 16 February 2020

Accepted: 25 February 2020

\section{*Correspondence:}

Dr. D. Vijayalakshmi,

Email: vijayadonipati@yahoo.in

Copyright: ( ) the author(s), publisher and licensee Medip Academy. This is an open-access article distributed under the terms of the Creative Commons Attribution Non-Commercial License, which permits unrestricted non-commercial use, distribution, and reproduction in any medium, provided the original work is properly cited.

\begin{abstract}
Background: Stroke, as a one of the leading causes of mortality and disability, is also very preventable and curable disease. Pharmacotherapy plays an important role in prevention of first-ever stroke as well as secondary cerebrovascular accident. We aimed to evaluate the prescription pattern in cases of ischemic stroke and to check whether rationale prescription of drugs in ischemic stroke patients is being followed in our hospital.

Methods: A prospective observational study was conducted in inpatient department of general medicine in government general hospital, Kakinada for a period of six months from April to September 2018. A total of 306 prescriptions of ischemic stroke were selected randomly and prescriptions patterns were assessed and analyzed.

Results: Out of the 306 cases, 183 were males (59.80\%) and 123 were female (40.19\%). Aspirin was given in $88.23 \%$ of the patients, Atorvastatin in $97.05 \%$, Clopidogrel in $24.50 \%$, antihypertensives in $67.64 \%$, B complex in $88.23 \%$, Pantoprazole in $85.29 \%$ of the patients. Physiotherapy was advised in $47.05 \%$ of the patients. Among anti hypertensives, Amlodipine was given in $73.91 \%$ patients.

Conclusions: Anti hypertensives, lipid lowering agents like Atorvastatin along with anti-platelet drugs like Aspirin and Clopidogrel were commonly prescribed for ischemic stroke cases for treatment and secondary prevention. Antacids and Multivitamin tablets were given as concomitant drugs. Present study showed a rationale utilization of drugs in ischemic stroke patients.
\end{abstract}

Keywords: Drug utilisation study, Ischemic stroke, Prescription pattern

\section{INTRODUCTION}

A stroke, or cerebrovascular accident, is defined as an abrupt onset of a neurologic deficit that is attributable to a focal vascular cause. ${ }^{1}$ After coronary heart disease (CHD) and cancer of all types, stroke is the third commonest cause of death worldwide. ${ }^{2}$ Stroke, as a one of the leading causes of mortality and disability, is also very preventable and curable disease. Ten risk factors (i.e. history of hypertension, current smoking, obesity measured with waist-to-hip ratio, diet, physical activity, diabetes mellitus, alcohol intake, psychosocial stress and depression, cardiac causes and dyslipidemias) are associated with $90 \%$ of the risk of stroke. ${ }^{3}$ Some of these risk factors can be addressed with specific and effective drug treatment. Therefore, apart from non-drug prevention methods, pharmacotherapy plays an important role in prevention of first-ever stroke as well as secondary cerebrovascular accident.

Indian population is relatively young compared with the Western countries but India has already attained epidemic proportions of annual incidence of stroke 145/100,000 
per year during 2003-06., ${ }^{4,5}$ Stroke mortality rate in India is 22 times that of malaria and 1.4 times that of tuberculosis. By 2025, four out of five stroke events will occur in people living in India. ${ }^{4}$

Current guidelines in the primary prevention of stroke recommend targeting some of the modifiable risk factors with a specific drug. Secondary prevention follows the primary management, although intensification of treatment is well recognized as some modifications. ${ }^{5}$ A number of medical and surgical interventions, as well as lifestyle modifications, are available for preventing stroke. Identification and control of modifiable risk factors is the best strategy to reduce the burden of stroke. Hypertension is the most significant of the risk factors. ${ }^{1}$

Various anti-hypertensive agents like Angiotensin converting enzyme inhibitors, Angiotensin receptor blockers, thiazide diuretics, calcium channel blockers are being used to control it. Statins are also used in stroke cases as several trials have confirmed that statin drugs reduce the risk of stroke even in patients without elevated LDL or low HDL.

Platelet antiaggregation agents can prevent atherothrombotic events, including TIA and stroke, by inhibiting the formation of intra-arterial platelet aggregates. Aspirin, clopidogrel, and the combination of aspirin plus extended-release dipyridamole are the antiplatelet agents most commonly used for this purpose. The long-term use of clopidogrel in combination with aspirin is not recommended for stroke prevention. The short-term combination of clopidogrel with aspirin may be effective in preventing second stroke. The choice of antiplatelet agent and dose must balance the risk of stroke, the expected benefit, and the risk and cost of treatment. ${ }^{1}$

The modifiable risk factors of stroke are on the rise worldwide thereby increasing the chances of stroke. There are many studies conducting on stroke cases but comparatively lesser studies were done on ischemic stroke cases alone. This is the rationale for conducting the study as it provides an insight into the present treatment strategies being followed for ischemic stroke cases in India.

The aim of this study was to evaluate the prescription pattern in cases of ischemic stroke in our hospital and to check whether rationale prescription of drugs in ischemic stroke patients is being followed in our hospital.

\section{METHODS}

A prospective observational study was conducted in inpatient department of General Medicine in Government General Hospital, Kakinada for a period of six months from April 2018 to September 2018.

\section{Inclusion criteria}

Inpatient prescriptions of ischemic stroke and patients of both sexes aged $18-80$ years.

\section{Exclusion criteria}

Outpatient prescriptions and hemorrhagic stroke prescriptions.

A sample size of 306 prescriptions were obtained after considering inclusion and exclusion criteria. The required information was collected from the case sheets of 306 patients from the General Medicine Department in Government general hospital and prescriptions patterns were assessed. Statistical analysis was done by using Microsoft Excel and depicted as Percentages. Institutional Ethics committee approval at Government General Hospital Kakinada has been taken to conduct this study.

\section{RESULTS}

The results from the 306 prescriptions were collected and assessed depicted in percentages. Figure 1 shows out of the 306 cases, 183 were males $(59.80 \%)$ and 123 were female $(40.19 \%)$. The new cases of ischemic stroke were 114 and 192 were old diagnosed cases.

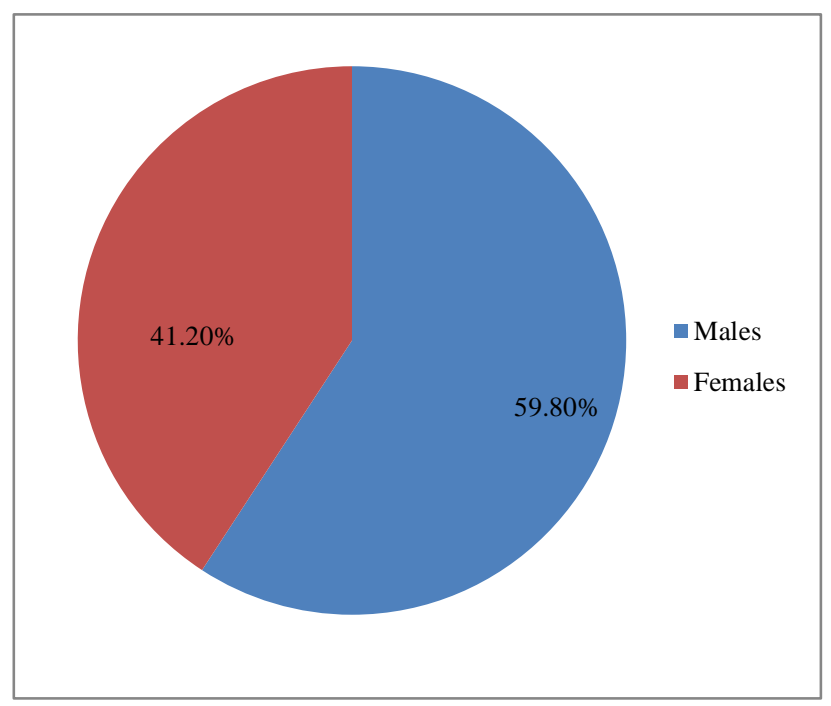

Figure 1: Distribution of sex in the group

The prescriptions of patients between 18 years to 80 years of age were taken for the current study. In this, 42 cases $(13.72 \%)$ were reported in the age group of 18-60 years. 118 patients $(38.57 \%)$ were reported to be in the age group of 61-70 years. The maximum number of patients was reported in the age group of 71-80 years with 146 cases $(47.71 \%)$.

Out of all the drugs prescribed to ischemic stroke cases, Aspirin is the most prescribed anti platelet drug 
prescribed in 270 patients $(88.23 \%)$ followed by Clopidogrel in 75 patients $(24.5 \%)$. Statins, which have a role in secondary prevention of ischemic stroke, were prescribed in most of the cases. Atorvastatin was the most prescribed statin in our hospital given to 297 patients $(97.05 \%)$ as shown in Figure 2.

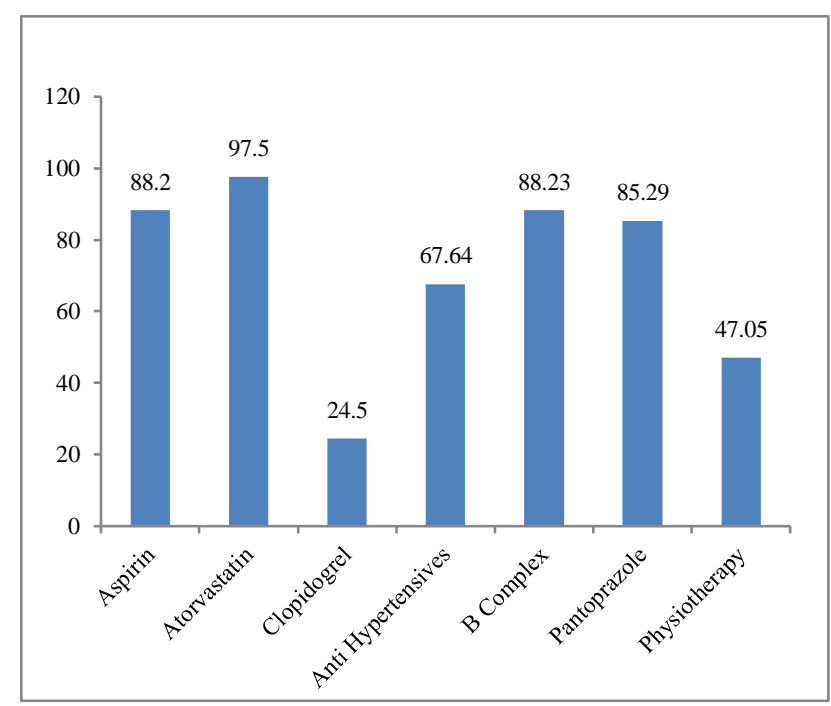

Figure 2: Prescription pattern of various drugs in ischemic stroke cases in percentage.

In this study, patients with hypertension were treated with different classes of antihypertensive in 207 cases $(67.64 \%)$. Calcium channel blocker Amlodipine was given in 153 cases $(50 \%)$ in our hospital. Others anti hypertensives prescribed were Beta adrenergic blocker Metoprolol in 22 cases $(5.88 \%)$ and Angiotensin converting enzyme inhibitor Enalapril in 32 cases $(8.82 \%)$.

Physiotherapy was advised to 144 patients (47.05\%) in our hospital to overcome any muscle weakness. B complex was prescribed in 270 patients $(88.23 \%)$ and antacid Pantoprazole was prescribed in 261 patients $(85.29 \%)$.

\section{DISCUSSION}

Drug utilization in ischemic stroke cases is important in monitoring of the current medical practice. It can also show the benefit of pharmacotherapy in real world settings. Males are more susceptible to stroke compared with females, this may be due to risk factors and lifestyle.

In present study population of 306 patients, 183 were males $(59.80 \%)$ and 123 were female $(40.19 \%)$. In the study done by Niewada et al in Poland, females represented $51.6 \%$ of the registered population while males represented $48.4 \% .^{6}$ In RM Mudhaliar et al study out of 90 patients, $60(66.67 \%)$ were male and 30 $(33.33 \%)$ were female. ${ }^{7}$ Another study done in Malaysia, Hwong et al revealed that $2913(55 \%)$ and $2379(45 \%)$ were men and women respectively. ${ }^{8}$ In a study population of 14529, males were 7290 (50.2\%) and women 7239 $(49.8 \%)$ conducted by Signild et al in Sweden. ${ }^{9}$

In the present study, calcium channel blockers were the most prescribed anti hypertensives. Amlodipine was the calcium channel blockers prescribed in 153 cases $(50 \%)$. The angiotensin converting enzyme inhibitors (ACE inhibitors) drugs were less prescribed, Enalapril was prescribed to $32(8.82 \%)$ patients. While Beta blockers were prescribed in 22 cases $(5.88 \%)$ only. Eva et al also reported that 7843 patients were prescribed by ACE inhibitors and angiotensin antagonist, 9025 and 4459 patients were prescribed by beta blockers and calcium channel inhibitors, respectively. ${ }^{10}$ In Hwong et al study conducted in Malaysia Angiotensin-converting-enzymes inhibitors (ACEIs) recorded the highest number of prescriptions (65\%) whereas ACEIs and calcium channel blockers were the most commonly prescribed dual combination. $^{8}$

In Abbasi et al study anti hypertensives prescribed were beta blockers inclusing Metoprolol 7 (6.86\%), Atenolol 4 $(3.92 \%)$, Calcium channel blockers including Amlodipine 26 (25.49\%), Nifedipine $22(21.55 \%)$ ACE Inhibitors Ramipril 3 (2.94\%) Angiotensin antagonist Olmisertan 3 (2.94\%) Telmisertan 3 (2.94\%) Antihypertensive combination therapy Amlodipine + Atenolol 9 (8.82\%) Telmisertan + Hydrochlorthiazides 11 (10.78\%). ${ }^{4}$ In Mudhaliar RM et al study Beta blockers were the most prescribed anti hypertensives in 48 cases- Metoprolol (20), Carvedilol (17), Atenolol (7), combination of Metoprolol and Nifedipine (4). Amlodipine (19) Nifedipine (15) were the Calcium channel blockers prescribed in this study. Diuretics were prescribed in 34 cases Furosemide (13), Spiranolactone (9), combination of Ramipril, Telmisartan, Hydrochlorthiazide (2) and Mannitol (10). ACEIs and ARBs were less prescribed Ramipril (5), Telmisartan (6) and Losartan (3). ${ }^{7}$

The high proportion of patients receiving antiplatelet in this study was consistent with previous studies. In the present study, Aspirin is the most prescribed anti platelet drug prescribed in 270 patients $(88.23 \%)$ followed by Clopidogrel in 75 patients $(24.5 \%)$. In the study conducted by Abbasi MY et al the most popular antiplatelet was clopidogrel, which was prescribed to 48 (47.05\%) patients, while Aspirin was given in 2 (1.96\%) patients and Aspirin + Clopidogrel was given in 44 $(43.13 \%)$ patients. ${ }^{4}$ In Mudhaliar et al study, anti platelet drugs prescribed were Clopidogrel (32) Aspirin (13) Clopidogrel and Aspirin (40) cases. $^{7}$ 
Table 1: Comparison of various drugs prescribed in current study with other studies.

\begin{tabular}{|lllll|} 
Drugs prescribed & Current study $(\%)$ & $\begin{array}{l}\text { Abbasi et al study } \\
(\%)\end{array}$ & $\begin{array}{l}\text { Mudhaliar et al } \\
\text { study }^{7}(\%)\end{array}$ & $\begin{array}{l}\text { Hwong et al study }^{\mathbf{8}} \\
(\%)\end{array}$ \\
\hline Aspirin & 88.2 & 1.96 & 45.52 & 88 \\
\hline Atorvastatin & 97.5 & 19.6 & 12.12 & 88.7 \\
\hline Clopidogrel & 24.5 & 47.05 & 26.31 & - \\
\hline Antihypertensives & 67.64 & 86.27 & 1.58 & 48 \\
\hline Anticoagulants & - & 43.13 & - & 33 \\
\hline
\end{tabular}

In the current study statins were given in 297 cases. Among the statins Atorvastatin was the only drug being given in our hospital. In Abbasi et al study, Dyslipidimics were administered to $22(21.56 \%)$ patients; among them, $20(19.6 \%)$ patients were administered Atorvastatins 10 $\mathrm{mg}$ and the other $2(1.96 \%)$ patients Rosuvastatins $10 \mathrm{mg}$ were administered. ${ }^{4}$ In the Hwong et al study, the lipid lowering agents were given in $88.7 \%$ of the cases. ${ }^{8}$ In this study, physiotherapy was advised to 144 patients $(47.05 \%)$ to overcome any muscle weakness. B complex was prescribed in 270 patients $(88.23 \%)$ and antacid Pantoprazole was prescribed in 261 patients (85.29\%).

\section{Limitations}

The limitation of present study was that the data obtained is only specific to the site of study. But the usage of drugs in ischemic stroke may be different at different hospitals in India, due to physician's choice and preferences. This study could have been conducted as a multicentric study in large population to overcome this limitation

\section{CONCLUSION}

In this study, most of the patients were administered Atorvastatin as Dyslipidimic drug to reduce higher cholesterol and for secondary prevention of stroke. Aspirin was the most prescribed anti platelet drug followed by Clopidogrel for ischemic stroke cases. The complete study shows that various Anti hypertensives like calcium channel blockers (Amlodipine), Beta adrenergic blocker (Metoprolol) and Angiotensin converting enzyme inhibitors like (Enalapril) were used. Physiotherapy was advised in many cases to overcome muscle weakness. Antacids (Pantoprazole) and Multivitamin tablets were given as concomitant drugs. Present study showed a rationale utilization of drugs in ischemic stroke patients in our hospital.

\section{ACKNOWLEDGEMENTS}

I sincerely acknowledge my parents Mr. S. Ravindranath and Mrs. Aruna kumari, and my wife Mrs. Sailaja for staying beside me and supporting me all through my study. I thank my guide Dr. D. Vijayalakshmi MD and HOD Dr. P. Usha Kiran MD DM, Department of Pharmacology for their guidance and support in the study. I am happy to thank my friends (Ramya, Rupa, Sweta,
Preethi, Kauser, Vasu) for giving support. I would like to thank all postgraduates, clinicians and medical records department in Rangaraya medical college who helped me for the study.

\section{Funding: No funding sources}

Conflict of interest: None declared

Ethical approval: The study was approved by the Institutional Ethics Committee

\section{REFERENCES}

1. Longo DL, Fauci AS, Kasper DL, Hauser SL, Jameson JL, Loscalzo J, editors. Harrison's manual of medicine. New York: McGraw-Hill Medical; 2017.

2. Tapas K, Shyamal KD. Epidemiology of stroke in India. Neurol Asia. 2006;11(1):1-4.

3. Martin JD, Denis X, Lisheng L, Hongye Z, Lim CS, Purnima RM, et al. Risk factors for ischaemic and intracerebral haemorrhagic stroke in 22 countries (the INTERSTROKE study): a case-control study. Lancet. 2010;376(9735):112-23.

4. Abbasi MY, Ali MA. Prescribing pattern of drugs in stroke patients: A prospective study. Arch Phar Pract. 2012;3(4)283-8.

5. Johnston SC, Mendis S, Mathers CD. Global variation in stroke burden and mortality: estimates from monitoring, surveillance, and modelling. Lancet Neurol. 2009;8(4):345-54.

6. Niewada M, Sarzyńska-Długosz IM, Skowrońska M, Kamiński B, Kobayashi A, Członkowska A. Pharmacotherapy prior to and in acute ischaemic stroke. The use of pharmacotherapy and drugsassociated outcomes in real-world practice-findings from the Polish Hospital Stroke Registry. Neurologia i neurochirurgia polska. 2013;47(6):509-16.

7. Mudhaliar RM, Dungavath S, Yiragamreddy PR, Venkataramana B. Drug use evaluation and appropriateness of medication used in stroke patients. World J Pharm Med Res. 2016;2(5):168-74.

8. Hwong WY, Aziz ZA, Sidek NN, Bots ML, Selvarajah S, Kappelle LJ, et al. Prescription of secondary preventive drugs after ischemic stroke: results from the Malaysian National Stroke Registry. BMC Neurol. 2017;17(1):203.

9. Åsberg S, Henriksson KM, Farahmand B, Asplund K, Norrving B, Appelros P, et al. Ischemic stroke and secondary prevention in clinical practice: a cohort 
study of 14529 patients in the Swedish Stroke Register. Stroke. 2010;41(7):1338-42.

10. Glader EL, Sjölander M, Eriksson M, Lundberg M. Persistent use of secondary preventive drugs declines rapidly during the First 2 years after stroke. Stroke. 2006;41:397-401.
Cite this article as: Jagannath SV, Vijayalakshmi D. Prescription pattern in cases of ischemic stroke in general medicine department in Government General Hospital, Kakinada, Andhra Pradesh. Int J Basic Clin Pharmacol 2020;9:577-81. 